\title{
Polycyclic Aromatic Hydrocarbons in Urban Stream Sediments
}

\author{
Jejal Reddy Bathi, ${ }^{1,2}$ Robert E. Pitt, ${ }^{1}$ and Shirley E. Clark ${ }^{3}$ \\ ${ }^{1}$ Department of Civil, Construction and Environmental Engineering, The University of Alabama, Tuscaloosa, AL 35487, USA \\ ${ }^{2}$ Global Solutions International, LLC, P.O. Box 223, Mobile, AL 36652, USA \\ ${ }^{3}$ Penn State Harrisburg, Environmental Engineering Program, Middletown, PA 17057, USA \\ Correspondence should be addressed to Jejal Reddy Bathi, jejalb@gmail.com
}

Received 27 July 2011; Revised 20 November 2011; Accepted 16 December 2011

Academic Editor: Cumaraswamy Vipulanandan

Copyright ( $\odot 2012$ Jejal Reddy Bathi et al. This is an open access article distributed under the Creative Commons Attribution License, which permits unrestricted use, distribution, and reproduction in any medium, provided the original work is properly cited.

Polycyclic aromatic hydrocarbons (PAHs) are persistent organic pollutants of high environmental concern with known carcinogenic activity. Although literature documents PAH fate in urban runoff, little is known about their distribution on sediment sizes, which is essential for determining their treatability and fate in receiving waters. This paper has quantified the concentrations of selected PAHs in urban creek sediments and examined possible relationships between sediment PAH content and sediment characteristics, such as particle size, volatile organic content (VOC), and sediment chemical oxygen demand (SCOD). SCOD, VOC, and PAH concentrations of sediments showed a bimodal distribution by particle size. The large diameter sediments had the highest VOC and also had the highest PAH concentrations. The spatial variation of PAH content by sediment sizes also was statistically significant; however, the mass of the PAH material was significantly affected by the relative abundance of the different particle size classes in the sediment mixtures.

\section{Introduction}

Polycyclic aromatic hydrocarbons (PAHs) are a class of frequently detected organic pollutants in urban stormwater runoff. According to Metre et al. [1], PAH levels in urban freshwater sediments in North America have increased over time, indicating additional discharges associated with industrialization and urbanization, including increased use of vehicles and wear and tear of asphalt [1-3]. For example, Stein et al. [4] found PAHs in storm fluxes ranged from $1.3 \mathrm{~g} / \mathrm{km}^{2}$ for the largely undeveloped Arroyo Sequit watershed to $224 \mathrm{~g} / \mathrm{km}^{2}$ for the highly urbanized Verdugo Wash watershed in California, USA. Similarly, according to Huston et al. [5], there is an increase in the PAHs and other contaminant flux in traffic and industrial areas compared to outer suburbs, implicating these developments positively influencing PAHs contribution in the runoff. The relative distribution of individual PAHs in stormwater runoff can indicate their originating source category, with high molecular weight PAHs indicating pyrogenic (combustion) sources, whereas low molecular weight PAHs indicating petrogenic sources. However, tracking sources in this manner becomes questionable if the expected environmental biological or physical degradation processes change the relative abundance of the different PAHs in runoff. Regardless of the type of PAH source in urban areas, stormwater is a major delivery system of PAHs to receiving water bodies. It is important to understand the behavior of PAHs at their source and sink, that is, in stormwater and in nearby streams, in order to address their effective control and remediation. Since contaminated runoff also poses a risk to the aquatic environment, the presence of these compounds can result in regulatory demands for sediment assessment and remediation, or requirements for stormwater management controls or treatment [6].

PAHs in urban runoff can occur both in soluble and particulate-associated forms. Studies have identified particulate associated PAHs as the most abundant [7-10], which is expected based on their hydrophobic nature and low vapor pressure, especially for PAHs with more than three aromatic rings. Studies have also documented the impact of sediment texture and organic content affecting PAH associations with sediment [11]. Investigations have found high $\mathrm{PAH}$ concentrations associated with large organic material 
(leaf and other vegetation litter) trapped in stormwater floatable controls [12], further indicating that sediment composition affects the PAHs association with particulate matter, especially those solids high in organic content. Li et al. [13] also observed a strong positive relation between sediment total organic carbon or black carbon and its PAH concentrations. In addition, source areas may affect the distribution pattern of PAHs with sediment particle sizes. For example, Guggenberger et al. [14] noticed homogenous distributions of PAHs by particle sizes in rural soils, whereas Müller et al. [15] observed nonhomogeneous distributions of PAHs in urban soils. Biodegradation is one of the primary degradation processes for PAH reductions in sediments [16], and which might be affected by many factors including sediment size and hence the relative abundance of PAHs by sediment size. Relatively extensive data is available to confirm the major distribution fate of PAHs between dissolved and particulate form. However, limited information is available regarding distribution fate of the PAHs by particle sizes, which is the focus of this study.

Studies have looked at the particle size distribution in stormwater runoff and have attributed differences between studies to factors including source area, geographic location, and antecedent dry period. The transport energy available to move the larger particles through the urban drainage system is limited, with the large particles being deposited along the flow path or within the drainage system. Hence stormwater samples obtained near sediment sources contain more of the larger particles, whereas samples obtained at outfalls have fewer of the larger solids. The National Urban Runoff Pollution (NURP) study examined stormwater runoff data collected at outfalls from different locations in the USA and noted that more than $90 \%$ of the stormwater particulates (by volume and mass) were in the 1 to $100 \mu \mathrm{m}$ range [17]. Because of their strong association with solids in stormwater runoff, the fate and transport of PAHs will be directly related to their association with particle size. Associations with smaller particles likely result in further transport, less sedimentation in the drainage system, and potential treatment using filtration systems. For PAHs associated with larger particles, it can be anticipated that during most storm conditions, they will settle closer to the source and sedimentation will be a very effective control practice. Hence, the sampling location relative to the source area may influence the abundance of particle sizes as well PAH mass in the sample, which makes it is critical to better understand the particle size influenced association of PAHs.

Due to the trace concentrations of selected PAHs on stormwater particles and need for large sample volumes to separate stormwater solids into aliquots for PAH analysis, large sample volumes are required, which is difficult to achieve in most stormwater sampling situations. A surrogate for the representation of PAH associations by particle size would be to analyze the surficial sediment in urban receiving waters at the stormwater outfall. Such sampling may not give the true representation of the source stormwater particle distribution, but it will be adequate to quantify the expected PAHs concentration on sediment particle sizes for the source areas draining to that outfall. Careful selection of the outfall to isolate specific sources and landuses will allow for an improved understanding of source PAH generation and transport within the drainage system. This project used this approach to characterize PAH distribution by stormwater particle sizes and to test the influence of contributing source areas on such distribution. This project focused on collecting urban stream sediments located immediately downstream of stormwater outfalls in completely developed watersheds. The samples were obtained in a variety of urban streams in the Tuscaloosa and Northport, AL area, as described later. The range of sample characteristics is intended to represent the typical range of local urban stream conditions (particle sizes, contaminant concentrations, etc.). This study also examined the relationships between the urban creek sediment characteristics such as particle size distribution (psd), Volatile Organic Carbon (VOC), and Sediment Chemical Oxygen Demand (SCOD) with the PAH concentrations. Relationships such as these may allow stormwater managers to estimate the magnitude of $\mathrm{PAH}$ problems and associations based on more directly and easily measurable characteristics of the sediment.

This paper presents observed size distributions of sediment samples and PAH concentrations by particle size ranges. Results of tests for possible relationships between sediment PAH concentrations and respective sediment characteristics are also described in this paper.

\section{Methodology}

2.1. Source Area, Sample Collection, and Sample Processing. Fifteen separate sediment samples were collected from three different urban creeks (Cribbs Mill Creek, Hunter Creek, and Carroll Creek) in and around Tuscaloosa and Northport, AL, USA. Cribbs Mill Creek drained single-family, medium-tohigh density residential areas, while Hunter Creek received stormwater runoff from a heavily trafficked road next to the creek, commercial areas (including automotive repair facilities), and runoff from a trailer park residential area. Carroll Creek was mostly affected by runoff from a highdensity residential area on one side of creek and forested lands on the other side of the creek. These three creeks and the samples, therefore, represent a wide range of typical urban characteristics.

Sediment subsamples were obtained using a manual, polypropylene dipper sampler. Each subsample was collected from the top $2 \mathrm{~cm}$ of sediment (approximately $1000 \mathrm{~g}$ wet weight per sample). Five subsamples per creek were collected within a 100 meter reach for each sample period and composited for analyses. Samples were placed in aluminum trays, dried at about $100^{\circ} \mathrm{C}$ to remove moisture. It was assumed that, since the analytes of interests (selected PAHs, as described below) in this study have boiling points above $200^{\circ} \mathrm{C}$, drying sediment samples at about $100^{\circ} \mathrm{C}$ for small residence time (approximately 12 hours) under normal pressure conditions will not cause any significant loss of analytes of interest from the sediment samples. Extended heating under pressurized conditions, though, could result desorption of analytes from solid matrices at a temperature below their boiling point. If there is any such loss in our 
study, it will be primarily for more volatile low molecular weight analytes such as naphthalene (boiling point $218^{\circ} \mathrm{C}$ ). However, as all samples were treated in similar manner, such effect will be equally applicable to all sample results and will not affect comparison analyses of the sample results presented in this paper. Dried sediments were sieved through $45,90,180,355,710,1.400$, and $2,800 \mu \mathrm{m}$ stainless steel sieves with mechanical shaking $(100 \mathrm{rpm}, 60 \mathrm{~min})$ prior to PAH and other analyses. The mechanical shaker used has throw-action sieving where the vertical throwing motion is overlaid with slight circular motion, which helps the particles to distribute over the sieve and as well fall back to interact with the sieve mesh and pass through the opening if the particles are sufficiently small. Sediment separation using a mechanical shaker is a commonly employed procedure because it is believed to produce sediment separation that is reproducible and precise. Large organic materials (LOM; leaves and other debris $>2.800 \mu \mathrm{m}$ ) were manually separated from the largest particle fraction and analyzed separately. Sediments collected on individual sieves and LOM fraction were weighed and stored in a refrigerator until they were analyzed.

2.2. Sediment Chemical Analysis. All sediment fractions were analyzed for thirteen PAHs (selected based on literature reports describing their common occurrence in urban stormwater and which were also noted to be highly toxic). The thirteen PAHs analyzed include Naphthalene, Fluorene, Phenanthrene, Anthracene, Fluoranthene, Pyrene, Benzo(a)anthracene, Chrysene, Benzo(b)fluoranthene, Benzo(a)pyrene, Indeno(1,2,3-cd) pyrene, Dibenz(a,h)anthracene, and Benzo(g,h,i)perylene. The sample preparation and analysis technique, reported in Bathi [18], used AutoDesorb (Scientific Instrument Services, Inc., Ringoes, NJ, USA) thermal extraction methods to extract the PAHs from the sediment for direct injection into a GC-MSD.

2.3. Sediment Material Composition and SCOD Analysis. The volatile organic content of the sediment fractions was determined using "Thermal Chromatography" (an expansion of the volatile solids analyses) techniques per Ray [19]. SCOD analysis of size fractionated sediments was conducted per reactor digestion HACH Method 8000 (http:// www.hach.com/).

\section{Results and Discussion}

3.1. Sediment Particle Size Distribution. Figure 1 shows the observed particle size distribution, of the urban creek sediments from the three locations. Overall, most of the particles were distributed in the range of 90 to $710 \mu \mathrm{m}$, with the medians ranging from about 200 to $710 \mu \mathrm{m}$. Only about $10 \%$ of the sample mass, on average, was greater than $1,000 \mu \mathrm{m}$. Lack of small particles in the samples reflects the transport of fines during high creek flows. Cribbs Mill Creek had more large particles and Carroll Creek had more small particles. Increased large-size sediments at the Cribbs Mill Creek sampling location was thought to be caused

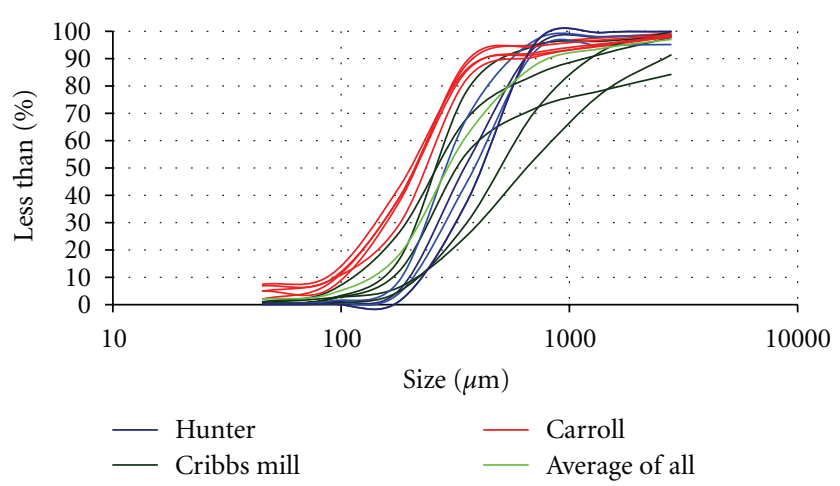

FIGURE 1: Observed creek sediment samples particle size distributions, by Mass.

by runoff from highly paved high-density urban areas as well the concrete lined creek bottom at the location that avoids dilution of the sediment particles with creek bottom erosion of smaller particles. In addition, the lined bottom also had considerable amounts of algae growth, which was included in larger size class of sediment samples. On the other hand, the Carroll Creek sample location's source area had large amounts of pervious areas. Hunter Creek was an intermediate location - it had a high percentage of paved areas in the drainage area, but with a natural creek bottom.

Compared to past studies of urban runoff samples (e.g., NURP), the creek sediment samples had lower percentages of smaller particles and higher percentages of larger particles, showing the likely deposition of the larger particles as creek sediment and the downstream transport of the smaller particles. These preferential removal mechanisms result in a shifted particle size distribution for the stream sediments compared to the particles in the stormwater discharges, as reported in the literature. As an example, the overall median particle sizes of the sampled stream sediments were between about 200 and $710 \mu \mathrm{m}$, which is about 50 to 100 times larger than the median particle sizes of most stormwater outfall particulates.

3.2. Sediment PAHs. The observed concentration of individual PAHs on size fractioned sediments with all samples combined from three locations are presented in Table 1. Observed PAH concentration within the sediment size fraction was highly variable (Table 1) and is similar to what one would expect for stormwater pollutants. Overall, the PAH analytical results showed a bimodal distribution of PAH concentrations with smaller $(<90 \mu \mathrm{m})$ and larger $(>710 \mu \mathrm{m})$ fractions having higher PAH concentrations, especially for the large organic matter (LOM). The trends are similar to what one would expect for semivolatile pollutant distributions in sediments given their low water solubility values and their propensity to be attracted to organic matter based on the literature, showing a strong positive correlation between the particles' organic content and their associated PAHs concentration. Based on the literature, it is expected that the smaller particles have a higher organic content in their mass [20], partly because of the native material (silts and clays) and 


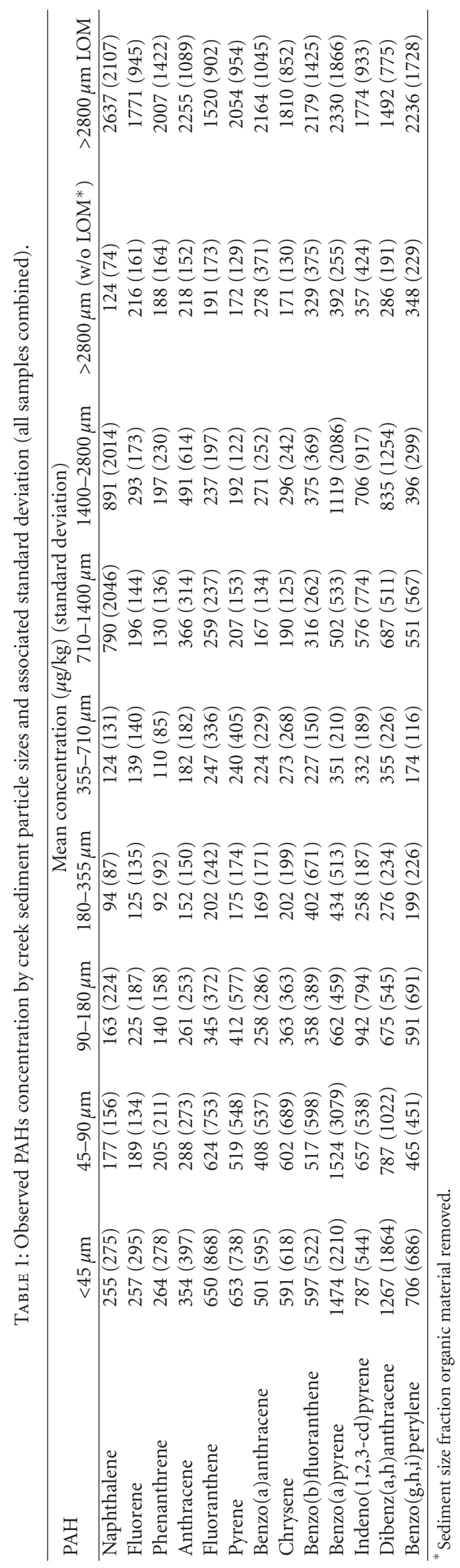


partly because of their ability to absorb dissolved organic matter in the water. The literature generally indicates a poor relationship between large mineral sediment sizes and PAH concentrations. This project, however, found that the large sediment particles, especially the LOM (large organic matter) samples that were of vegetation organic matter (leaves, grass clumps, etc.), had high PAH concentrations. These PAH concentrations correlated with the measured organic content of the sediment, which also showed the bimodal distribution.

The significant differences in PAHs concentration by particle size were verified using One-Way ANOVA analysis, and results of the test are presented in Table 2. Other than naphthalene at Cribbs Mill Creek and benzo(a)pyrene, indeno(1,2,3-cd)pyrene, and benzo(g,h,i)perylene at Hunter Creek, all PAHs analyzed at the three locations indicated significant differences in their concentration by sediment particle sizes ( $P$ value less than 0.05$)$. Cluster analyses of sediment PAH concentrations by particle size showed a separate single group for the $>2800 \mu \mathrm{m}$ LOM fraction for most of the PAHs, indicating a difference exists between LOM PAH concentrations and other sediment size fractions PAHs, see Bathi 2008 for full statistical analyses [18]. The two-way ANOVA analysis of PAH concentrations by particle size and sample location indicated that concentrations were affected by sediment particle sizes and, except for naphthalene, fluorene, phenanthrene, and indeno(1,2,3-cd)pyrene, PAH concentrations were influenced by the sample location. With few exceptions, the interaction of sediment location and particle size statistically influenced the PAH concentrations (Table 3).

Figures 2(a) and 2(b) illustrate the mass load of the PAHs by sediment particle size for the creek sediment samples. As expected, most of the PAH mass was associated with small and intermediate size sediments, as LOM $(0.6 \%)$ and the large mineral sediment sizes were only a small fraction of the total sediment. Since more than $90 \%$ of all stormwater particles are expected in the 1 to $100 \mu \mathrm{m}$ range and, given the observed higher concentrations of PAHs in the smaller sediment particles, most of the stormwater runoff PAH load would be expected to be associated with the finer particles. This is similar to findings by Stein et al. [4], who observed a strong and consistent pattern of high PAH concentrations in dissolved and fine particulate matter. Stein also found that between 30 and $60 \%$ of the total PAH load was discharged in the first $20 \%$ of the runoff volume for the studied storms and location.

This association of PAHs with the small and large particle sizes affects their treatability. In an advanced stormwater treatment device, the Multi-Chambered Treatment Train (MCTT), Pitt et al. [21] found that very high PAH removals occurred with sedimentation processes designed to remove $<5 \mu \mathrm{m}$ particles. Postsedimentation media treatment using mixtures of sand and peat reduced the PAH concentrations to below detection limits. PAH control data is sparse, but it is expected that simple sedimentation in well-designed wet detention ponds typically results in moderate $\mathrm{PAH}$ removals. Media filtration can be very effective in removing particles in the range of 1 to $5 \mu \mathrm{m}$, indicating that filtration/biofiltration
TABLE 2: One-way ANOVA Analysis of PAHs concentration by creek sediment particle size.

\begin{tabular}{lccc}
\hline \multirow{2}{*}{ PAH } & \multicolumn{3}{c}{ One-way ANOVA $P$ value } \\
& $\begin{array}{c}\text { Cribbs Mill } \\
\text { Creek }\end{array}$ & $\begin{array}{c}\text { Hunter } \\
\text { Creek }\end{array}$ & $\begin{array}{c}\text { Carroll } \\
\text { Creek }\end{array}$ \\
\hline Naphthalene & 0.324 & 0.000 & 0.000 \\
Fluorene & 0.000 & 0.000 & 0.000 \\
Phenanthrene & 0.000 & 0.000 & 0.000 \\
Anthracene & 0.000 & 0.000 & 0.000 \\
Fluoranthene & 0.000 & 0.000 & 0.000 \\
Pyrene & 0.000 & 0.000 & 0.000 \\
Benzo(a)anthracene & 0.000 & 0.000 & 0.000 \\
Chrysene & 0.000 & 0.001 & 0.000 \\
Benzo(b)fluoranthene & 0.000 & 0.011 & 0.000 \\
Benzo(a)pyrene & 0.039 & 0.060 & 0.000 \\
Indeno(1,2,3-cd)pyrene & 0.002 & 0.437 & 0.000 \\
Dibenz(a,h)anthracene & 0.024 & 0.010 & 0.000 \\
Benzo(g,h,i)perylene & 0.004 & 0.118 & 0.000 \\
\hline
\end{tabular}

TABle 3: Two-way ANOVA $P$ values comparing PAH concentration by sediment particles size and sample location.

\begin{tabular}{lccc}
\hline \multirow{2}{*}{ PAH } & \multicolumn{3}{c}{ Two-way ANOVA $P$ value } \\
& $\begin{array}{c}\text { Particle } \\
\text { size }\end{array}$ & $\begin{array}{c}\text { Sample } \\
\text { location }\end{array}$ & $\begin{array}{c}\text { Size and location } \\
\text { interaction }\end{array}$ \\
\hline Naphthalene & 0.000 & 0.088 & 0.116 \\
Fluorene & 0.000 & 0.721 & 0.481 \\
Phenanthrene & 0.000 & 0.389 & 0.043 \\
Anthracene & 0.000 & 0.032 & 0.821 \\
Fluranthene & 0.000 & 0.000 & 0.000 \\
Pyrene & 0.000 & 0.000 & 0.000 \\
Benzo(a)anthracene & 0.000 & 0.005 & 0.002 \\
Chrysene & 0.000 & 0.004 & 0.000 \\
Benzo(b)fluoranthene & 0.000 & 0.002 & 0.254 \\
Benzo(a)pyrene & 0.004 & 0.032 & 0.022 \\
Indeno(1,2,3-cd)pyrene & 0.000 & 0.284 & 0.250 \\
Dibenz(a,h)anthracene & 0.000 & 0.019 & 0.002 \\
Benzo(g,h,i)perylene & 0.000 & 0.041 & 0.493 \\
\hline
\end{tabular}

systems are likely very effective at treating PAH particulate matter.

3.3. Relating Sediment Composition, COD, and PAH Content. The thermal chromatography technique showed that the sediment sample, when heated from 240 to $365^{\circ} \mathrm{C}$, lost volatile organic content. The smaller $(<90 \mu \mathrm{m})$ and larger $(>710 \mu \mathrm{m})$ size fractions had higher percentage volatile organic content and COD than intermediate-sized particles (Table 4). The observed bimodal distribution of the volatile organic content and COD by sediment particle sizes was 

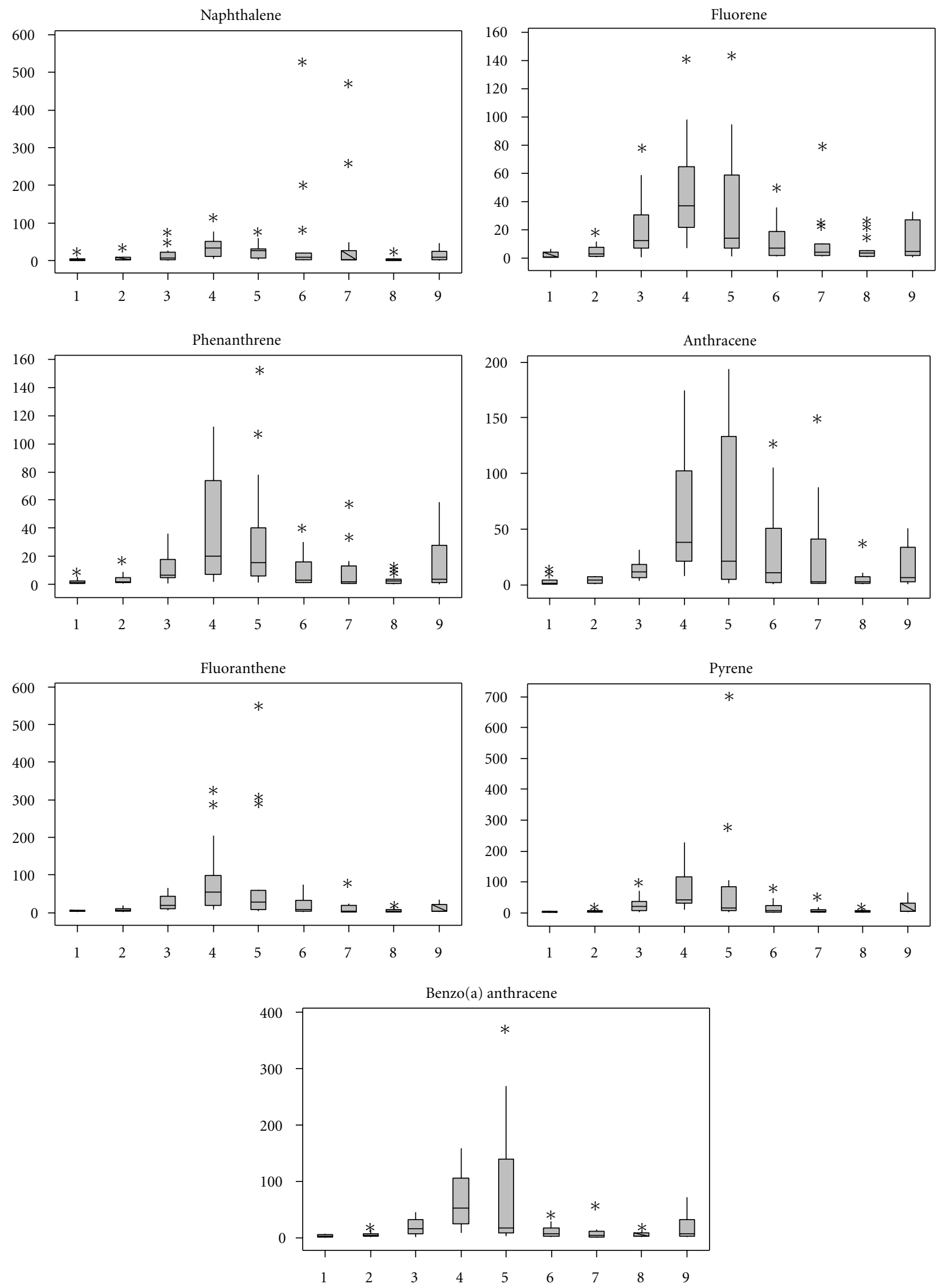

(a)

Figure 2: Continued. 

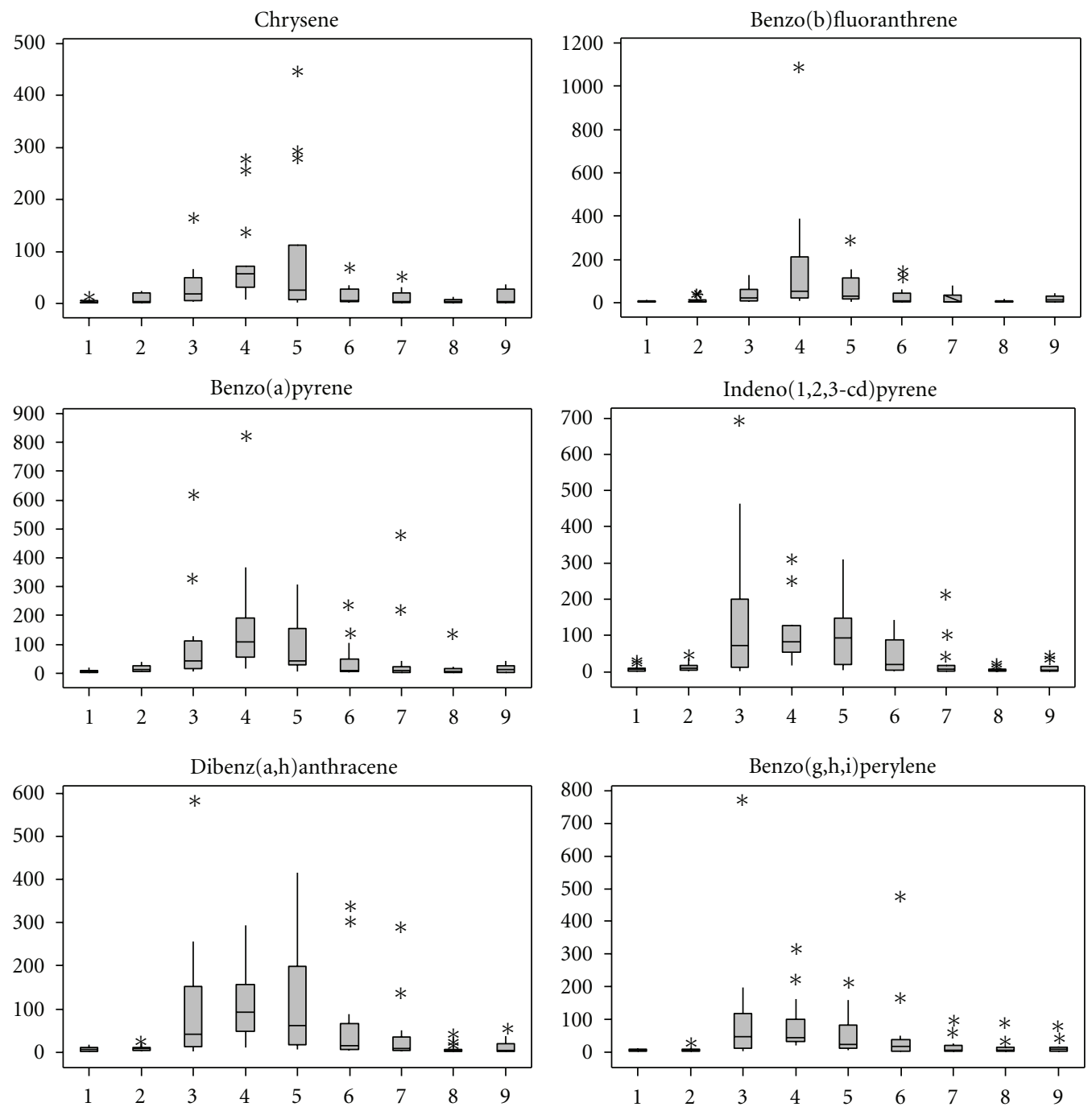

(b)

Figure 2: Observed mass distribution of analytes by sediment particle sizes. Notes: $x$-axis is particle size range $(\mu \mathrm{m})$, where $1=<45 ; 2=$ $45-90 ; 3=90-180 ; 4=180-355 ; 5=355-710 ; 6=710-1400 ; 7=1400-2800 ; 8=>2800$ (w/o LOM*); $9=>2800$ (LOM). * with large organic material removed. $y$-axis weight in $\mu \mathrm{g}$ of analyte associated with particle fraction in $1 \mathrm{~kg}$ of total sediment.

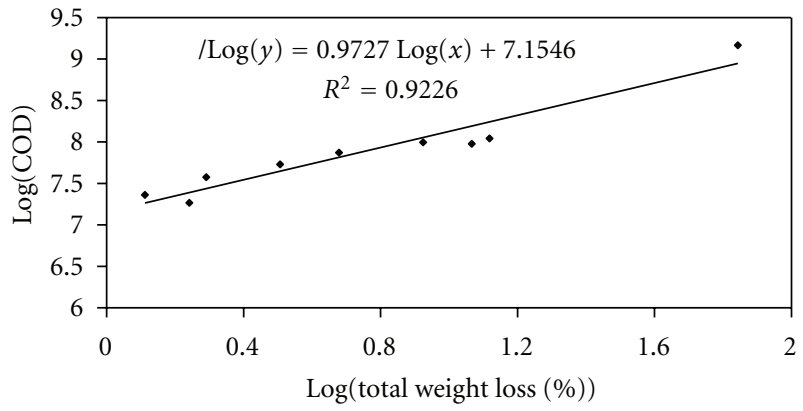

Figure 3: Log percentage of volatile content and log COD regression analysis.

similar to the distribution observed for PAH concentrations of the sediment fractions (Tables 1 and 4). Similarly, a strong, statistically significant linear relation was observed between measured sediment fraction COD and log transformed percent volatile organic carbon content (Figure 3 ).

Regression analyses were also employed to examining the relationships between COD and PAH content of the sediment samples. For regressions at each sampling location relating COD by particle size and their PAH content, the slope term of the regression was significant $(P<0.05)$ for 193 out of a total of 351 cases ( 9 particle size ranges, 13 analytes, and 3 locations). A larger number of significant cases were found for sediment fractions with higher volatile content (larger and smaller sediment fractions compared to intermediate sizes). There was no particular trend seen based on the PAH's molecular weight or number of aromatic rings for the PAH, indicating there is no clear evidence of varied affinity of the studied PAHs based on sediment organic content, irrespective of their molecular weights. 
TABLE 4: Thermal chromatography sediment volatile organic content and COD analysis results.

\begin{tabular}{|c|c|c|}
\hline Size range $(\mu \mathrm{m})$ & $\begin{array}{c}\% \text { Volatile organic } \\
\text { content }\end{array}$ & $\begin{array}{c}\text { SCOD } \\
(\mathrm{mg} / \mathrm{kg} \text { dry sediment })\end{array}$ \\
\hline$<45$ & 1.1 & 74,000 \\
\hline $45-90$ & 1.45 & 54,000 \\
\hline $90-180$ & 0.49 & 23,000 \\
\hline $180-355$ & 0.45 & 18,000 \\
\hline $355-710$ & 0.8 & 38,000 \\
\hline $710-1400$ & 3.54 & 99,000 \\
\hline $1400-2800$ & 6.39 & 110,000 \\
\hline$>2800($ w/o LOM*) & 6.51 & 95,000 \\
\hline$>2800 \mathrm{LOM}$ & 37.98 & $1,500,000$ \\
\hline
\end{tabular}

${ }^{*}$ With large organic material removed.

\section{Conclusions}

As expected for developed urban creeks that carry high runoff flows, the creek sediment samples were composed of fewer fines than would be expected in surface stormwater runoff samples. However, the concentrations of the contaminants in each particle size category are likely representative of the same particle size categories found in stormwater. These results can be used to characterize PAH characteristics by particle size in stormwater (in conjunction with a suitable particle size distribution), to indicate the likely transport and fate of discharged PAHs after discharge and to indicate the potential for stormwater treatment of particulate-bound PAHs. In this study, most of the sediment samples (by mass) were dominated by particles in the size range of $90-710 \mu \mathrm{m}$. Observed volatile organic content and SCOD and PAHs concentration of the size fractionated urban creek sediment particles showed a bimodal distribution: smaller and larger particles had relatively higher concentrations of organic content, PAHs, and SCOD than the intermediate particles. The presence of fragmentary plant material in the larger size fractions and the high clay/silt content along the high surface area in the smaller size fractions are believed to cause higher volatile organic content and hence the associated $\mathrm{PAH}$ concentrations in these size ranges. Among all the size fractions, highest $\mathrm{PAH}$ concentrations were observed in LOM fractions; however, LOM fractions represented only small portions of the sediment samples, by mass, and the amount of PAHs associated with these fractions also was small compared to other size fractions.

These results highlight the challenges associated with treating PAHs in urban runoff using traditional sedimentation methods. These small particle sizes are more favorably removed using treatment technologies such as media filtration, although large amounts can be removed by welldesigned sedimentation practices. Sedimentation, therefore, should precede any media filter treatment method as a pretreatment unit process. The associations with LOM indicate that floatables control will be needed to remove the organic matter (leaves, grass clippings) and associated PAHs. Overall, a treatment train containing complimentary unit processes such as floatable and grit control, sedimentation designed to remove small particles, and finally media treatment (as in the MCTT [21]) should result in excellent PAH removals from stormwater. This treatment approach can be expected to result in significant reductions of PAH contamination of urban stream sediments.

\section{Acknowledgment}

This material is based upon work supported by the National Science Foundation under Grant no. EPS-0447675. Any opinions, findings, and conclusions or recommendations expressed in this material are those of the author(s) and do not necessarily reflect the views of the National Science Foundation.

\section{References}

[1] V. P. C. Metre, B. J. Mahler, and E. T. Furlong, "Urban sprawl leaves its PAH signature," Environmental Science \& Technology, vol. 34, no. 19, pp. 4064-4070, 2000.

[2] J. R. Kucklick, S. K. Sivertsen, M. Sanders, and G. I. Scott, "Factors influencing polycyclic aromatic hydrocarbon distributions in South Carolina estuarine sediments," Journal of Experimental Marine Biology and Ecology, vol. 213, no. 1, pp. 13-29, 1997.

[3] S. McCready, D. J. Slee, G. F. Birch, and S. E. Taylor, "The distribution of polycyclic aromatic hydrocarbons in surficial sediments of Sydney Harbour, Australia," Marine Pollution Bulletin, vol. 40, no. 11, pp. 999-1006, 2000.

[4] E. D. Stein, L. L. Tiefenthaler, and K. Schiff, "Watershed-based sources of polycyclic aromatic hydrocarbons in urban storm water, Environmental Toxicology and Chemistry, vol. 25, no. 2, pp. 373-385, 2006.

[5] R. Huston, Y. C. Chan, T. Gardner, G. Shaw, and H. Chapman, "Characterisation of atmospheric deposition as a source of contaminants in urban rainwater tanks," Water Research, vol. 43, no. 6, pp. 1630-1640, 2009.

[6] K. O'Reilly, J. Pietari, and P. Boehm, "PAHs review, Polycyclic aromatic hydrocarbons in stormwater and urban sediments," Stormwater, September 2010, http://www.stormh20.com.

[7] R. Pitt, R. Field, M. Lalor, and M. Brown, "Urban stormwater toxic pollutants: assessment, sources, and treatability," Water Environment Research, vol. 67, no. 3, pp. 260-275, 1995.

[8] E. A. Guertal, D. J. Eckert, S. J. Traina, and T. J. Logan, "Parking lot sealcoat: an unrecognized source of urban polycyclic aromatic hydrocarbons," Environmental Science \& Technology, vol. 39, no. 15, pp. 5560-5566, 2005.

[9] H. M. Hwang and G. D. Foster, "Characterization of polycyclic aromatic hydrocarbons in urban stormwater runoff flowing into the tidal Anacostia River, Washington, DC, USA," Environmental Pollution, vol. 140, no. 3, pp. 416-426, 2006.

[10] C. J. Diblasi, H. Li, A. P. Davis, and U. Ghosh, "Removal and fate of polycyclic aromatic hydrocarbon pollutants in an urban stormwater bioretention facility," Environmental Science \& Technology, vol. 43, no. 2, pp. 494-502, 2009.

[11] J. L. Zhou, T. W. Fileman, S. Evans et al., "Fluoranthene and pyrene in the suspended particulate matter and surface sediments of the Humber estuary, UK," Marine Pollution Bulletin, vol. 36, no. 8, pp. 587-597, 1998.

[12] B. Rushton, Broadway Outfall Stormwater Retrofit Project, Monitoring CDS Unit and Constructed Pond. South Florida 
Water Management District and City of Temple Terrace: W241, Brooksville, Fla, USA, 2006.

[13] H. Li, J. Chen, J. Wu, and X. Piao, "Distribution of polycyclic aromatic hydrocarbons in different size fractions of soil from a coke oven plant and its relationship to organic carbon content," Journal of Hazardous Materials, vol. 176, no. 1-3, pp. 729-734, 2010.

[14] G. Guggenberger, M. Pichler, R. Hartmann, and W. Zech, "Polycyclic aromatic hydrocarbons in different forest soils: mineral horizons," Zeitschrift fur Pflanzenernahrung und Bodenkunde, vol. 159, no. 6, pp. 565-573, 1996.

[15] S. Müller, W. Wilcke, N. Kanchanakool, and W. Zech, "Polycyclic aromatic hydrocarbons (PAHs) and polychlorinated biphenyls (PCBs) in particle-size separates of urban soils in Bangkok, Thailand," Soil Science, vol. 165, no. 5, pp. 412-419, 2000.

[16] A. K. Haritash and C. P. Kaushik, "Biodegradation aspects of Polycyclic Aromatic Hydrocarbons (PAHs): a review," Journal of Hazardous Materials, vol. 169, no. 1-3, pp. 1-15, 2009.

[17] Metropolitan Washington Council of Governments, Urban Runoff in the Washington Metropolitan Area. U.S. Environmental Protection Agency, Nationwide Urban Runoff Program, 1983.

[18] J. R. Bathi, Associations of polycyclic aromatic hydrocarbons (PAHs) with urban creek sediments, Ph.D. thesis, Department of Civil, Construction and Environmental Engineering, The University of Alabama, Tuscaloosa, Ala, USA, 2008.

[19] H. Ray, Street dirt as a phosphorus source in urban stormwater, MSCE, Department of Civil and Environmental Engineering, University of Alabama at Birmingham, Birmingham, Ala, USA, 1997.

[20] A. Krein and M. Schorer, "Road runoff pollution by polycyclic aromatic hydrocarbons and its contribution to river sediments," Water Research, vol. 34, no. 16, pp. 4110-4115, 2000.

[21] R. Pitt, B. Robertson, P. Barron, A. Ayyoubi, and S. Clark, Stormwater Treatment at Critical Areas: The Multi-Chambered Treatment Train (MCTT). U.S. Environmental Protection Agency, Wet Weather Flow Management Program, National Risk Management Research Laboratory, EPA/600/R99/017, Cincinnati, Ohio, USA, 1999. 

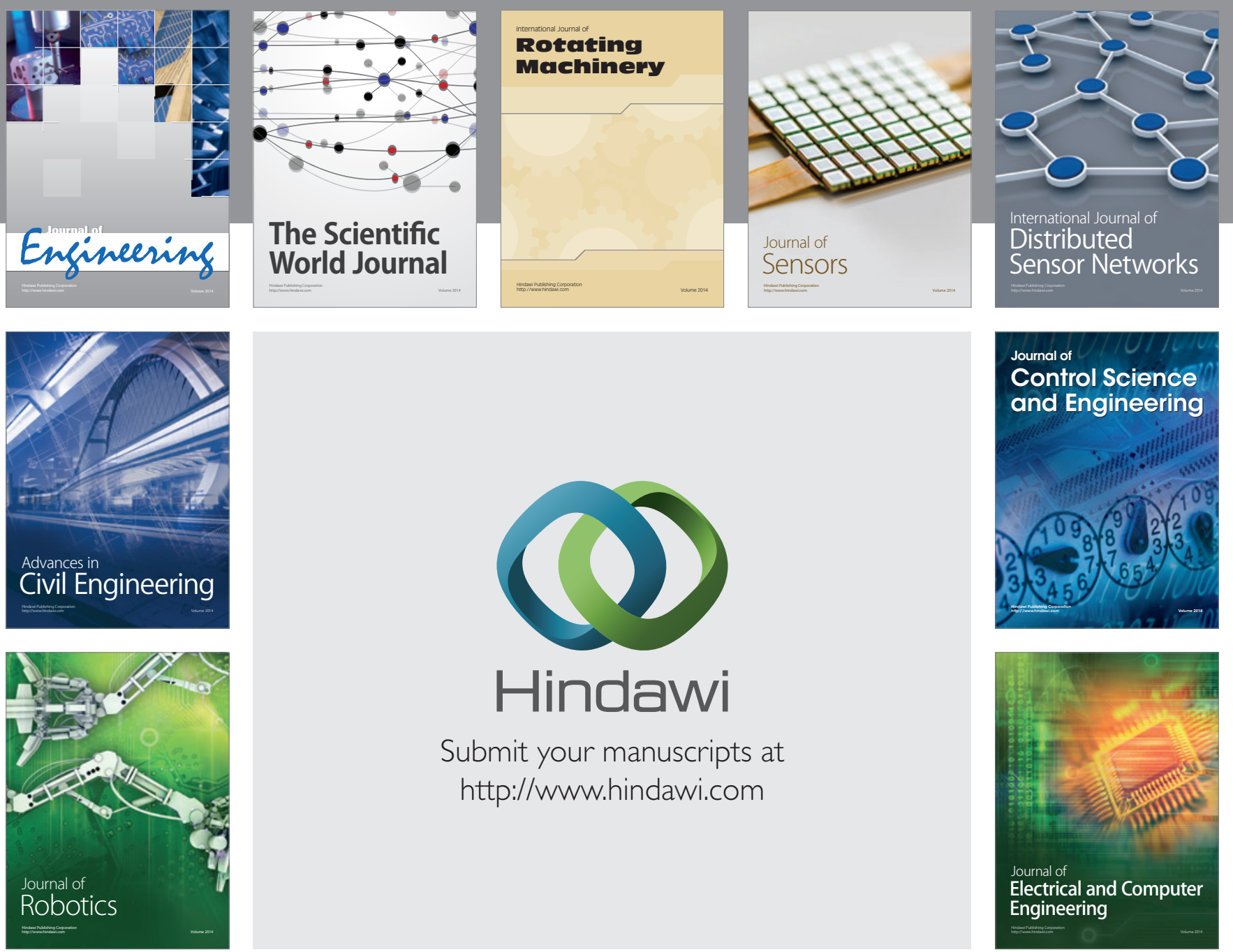

Submit your manuscripts at

http://www.hindawi.com
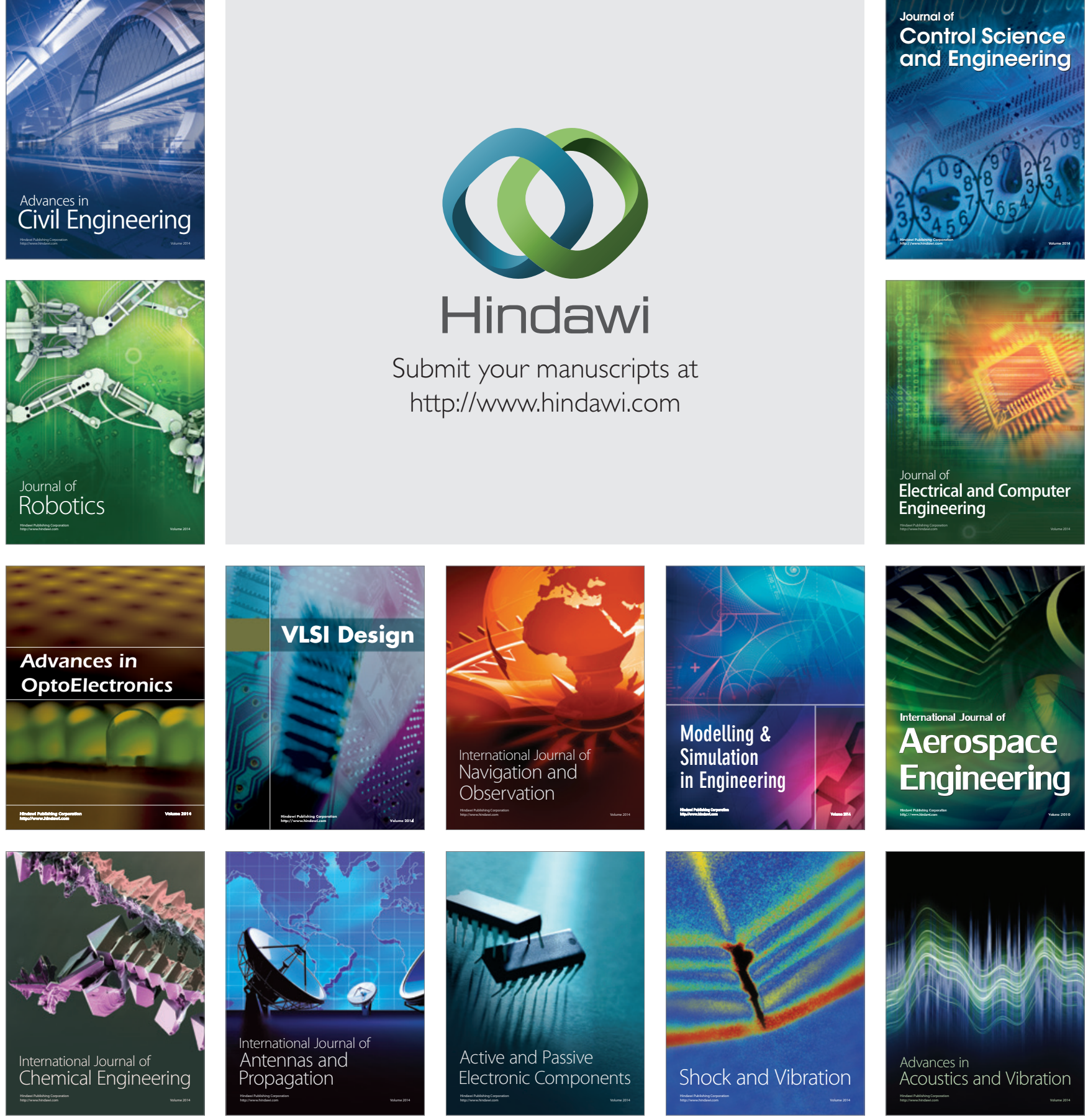